\title{
A novel real-time PCR assay for specific detection of Brucella melitensis
}

\author{
Rene Kaden ${ }^{1}$, Sevinc Ferrari ${ }^{2,3}$, Erik Alm ${ }^{4}$ and Tara Wahab 3 , $^{3, *}$
}

\begin{abstract}
Background: Brucellosis is a zoonosis that occurs worldwide. The disease has been completely eradicated in livestock in Sweden in 1994, and all cases of confirmed human brucellosis are imported into Sweden from other countries. However, due to an increase in the number of refugees and asylum seekers from the middle-east to Sweden, there is a need to improve the current diagnostic methodology for Brucella melitensis. Whilst culture of Brucella species can be used as a diagnostic tool, real-time PCR approaches provide a much faster result. The aim of this study was to set up a species-specific real-time PCR for the detection of all biovars of Brucella melitensis, which could be used routinely in diagnostic laboratories.

Methods: A Brucella melitensis real-time PCR assay was designed using all available genomes in the public database of Brucella $(N=96)$ including all complete genomes of Brucella melitensis $(N=17)$. The assay was validated with a collection of 37 Brucella species reference strains, 120 Brucella melitensis human clinical isolates, and 45 clinically relevant non-Brucella melitensis strains.

Results: In this study we developed a single real-time PCR for the specific detection of all biovars of Brucella melitensis. Conclusions: This new real-time PCR method shows a high specificity (100\%) and a high sensitivity (1.25 GE/ $\mu$ l) and has been implemented in the laboratories of four governmental authorities across Sweden.
\end{abstract}

Keywords: Brucella melitensis, Brucellosis, Real-Time PCR

\section{Background}

Despite ongoing eradication programs, brucellosis is a widespread zoonosis that infects mainly cattle, sheep, goats, and pigs. It also leads to considerable financial losses in animal husbandry due to abortion and fertility problems in cattle, sheep and goats $[1,2]$. Some Brucella species can also infect humans and more than 500,000 human cases are reported annually worldwide [3]. Brucellosis is a febrile illness, sometimes with localized bone and tissue infection, or multiorgan disease. Transmission to humans occurs through different routes: the ingestion of unpasteurized milk and dairy products; direct contact with infected animal tissues; or accidental ingestion, inhalation or injection of cultured Brucella [4]. Most human Brucellosis cases occur in Syria, Turkey, Mexico and Iran, but also around the

\footnotetext{
* Correspondence: tara.wahab@folkhalsomyndigheten.se

${ }^{3}$ Swedish Forum for Biopreparedness Diagnostics, Stockholm, Umeå and Uppsala, Sweden

${ }^{4}$ Department of Microbiology, The Public Health Agency of Sweden,

Stockholm, Sweden

Full list of author information is available at the end of the article
}

Mediterranean basin (Portugal, Spain, Southern France, Italy, Greece, Turkey, North Africa) [3]. Brucella comprises six classical species (B. abortus, B. canis, B. melitensis, $B$. neotomae, $B$. ovis, and $B$. suis) and five novel species (B. ceti, B. microti, B. inopinata, B. papionis and B. pinnipedialis). $B$. melitensis is recognized as the main human pathogen associated with human outbreaks worldwide [3, 5, 6]. The species of the genus Brucella can be distinguished on the basis of phenotype, genotype and preferred host. Sweden was officially declared free of brucellosis in 1994 [7] and all human cases in Sweden originate from countries abroad. The incidence in Sweden is between 1 and 20 reported cases per year according to the Swedish National Surveillance System SmiNet-2 [8]. The gold standard method for its diagnosis is the isolation of the bacteria from clinical samples via blood cultures and identification by classical microbiological tube testing. Brucella grows slowly and visible cultures appear after 3-4 days, but it can take more than 2 weeks to obtain a definitive result [9]. Due to its pathogenicity, a biosafety level 3 laboratory 
(BSL-3) is mandatory when handling Brucella organisms. Laboratory-acquired infections are rarely diagnosed or reported, however they do occur $[9,10]$.

The application of DNA-based methods for Brucella diagnosis is challenging, since all Brucella species have a very high degree of genetic homology (up till 99.9\%), as shown by whole genome sequencing of B. abortus, $B$. melitensis, and B. suis [11-14]. However, several groups have recently developed PCR-based assays for the discrimination among species and biovars of Brucella. Three Brucella species B. abortus, B. melitensis, and B. suis have been sub-typed into biovars $[15,16]$. All species within the genus Brucella show an average similarity of $99 \%$ across the entire genome and a range between 93\% and $99.9 \%$ based on analysis and nonparametric inference (ANI) analysis. Data from all public available complete genome sequences of all type strains and reference strains were included in the design of primers and probes for the real-time PCR assay of this study. One multiplex PCR (AMOS) developed by Bricker and Halling in 1994, is applicable to differentiate between B. abortus biovars 1, 2 and 4, B. melitensis, and B. ovis, B. suis biovar 1 by specific PCR products based on unique chromosomal loci of the mobile genetic element IS711 in their genome [17]. This PCR was later improved by another laboratory by adding specific primers for the identification of $B$. abortus biovars 5, 6, 9 and genotype 3b of biovar 3 [18]. In 2009, Huber et al. developed a random amplified polymorphic DNA PCR assay to differentiate all recognized Brucella species, including the marine mammals-infecting species $B$. ceti and B. pinnipedialis [19]. However, all published methods are developed to distinguish species and biovars mainly by gel-based bar patterns and the majority of described methods were tested with a few strains.

Kim et al. [20] developed a new real-time PCR for distinguishing $B$. abortus from other Brucella species, which is based on a single nucleotide polymorphism. However, there was a need for a reliable real-time PCR for the detection of $B$. melitensis at the species level [21]. The method has to be validated for clinical purposes with a large number of human isolates to fulfill the validation requirements of the certified laboratory of the public health institute. A Brucella genus specific realtime PCR assay is currently in use at the Public Health Agency in Sweden (FOHM). However, B. melitensis is the most prevalent species, and we need to be able to differentiate to the species level, due to the epidemiological significance of B. melitensis [21].

\section{Methods}

With the aim of developing a real-time PCR assay for the detection of all known species and biovars of $B$. melitensis, the genomes of $B$. ceti, $B$. inopinata, $B$. neotomae and $B$. suis biovar 4 were sequenced and analyzed.
This as necessary due to the lack of necessary genome data in the publicly available databases at the start of this project [14]. The panel to validate the inclusivity and exclusivity of the real-time PCR assay contained all known biovars of Brucella, as well as 45 other non-Brucella DNA from American Type Culture Collection (ATCC), Culture Collection University of Gothenburg (CCUG) and National Collection of Type Cultures (NCTC) with clinical relevance. A number of environmental samples, as well as the closely related species Ochrobactrum anthropi, were also tested in this study (Tables 1 and 2).

\section{Bacterial strains and growth conditions}

A collection of 31 Brucella sp. reference strains (Table 1) and $120 \mathrm{~B}$. melitensis human clinical isolates were isolated in the BSL-3 laboratory at the FOHM, by cultivation on $5 \%$ sheep blood agar plates in a $5 \%-10 \% \mathrm{CO}_{2}$ atmosphere at $37{ }^{\circ} \mathrm{C}$ for $48 \mathrm{~h}$. All non-Brucella strains were routinely cultivated on $5 \%$ sheep blood agar over night at $37^{\circ} \mathrm{C}$.

The B. melitensis human clinical isolates were collected between 1994 and 2016 from Swedish patients, who had returned from Brucella-endemic countries, in a biorepository of the FOHM and used as stipulated in the regulations for diagnostic development and quality assessment. The FOHM performs all Brucella diagnostics on human samples in Sweden, and the B. melitensis isolates used in this study have previously been confirmed by cultivation, a general real-time PCR amplifying DNA of all Brucella strains, as well as by Matrix Assisted Laser Desorption/Ionization Time of Flight Mass Spectrometry (MALDI-TOF MS) [22, 23]. Ethical review of research involving humans is not applicable for diagnostic development and quality assessment.

\section{DNA extraction}

Bacterial DNA was extracted using the commercially available EZ1 ${ }^{\circ}$ DNA Tissue Kit from (Qiagen, Stockholm, Sweden) according to the protocol from the manufacturer and stored at $4{ }^{\circ} \mathrm{C}$ until use. A volume of $5 \mu \mathrm{l}$ of seal herpes virus cell culture was used in each sample of the total volume of $200 \mu \mathrm{l}$ in the extraction step as a process control. Each sample was eluted in $50 \mu$ l elution buffer.

\section{Bioinformatic analyses, primer \& probe design and real-time $P C R$}

In order to identify a $B$. melitensis-specific target(s), all available genomes in the public database of Brucella $(N=96)$ including all complete genomes of $B$. melitensis $(N=17)$ were used in the design of primers and probes. A 2 basepair deletion which is highly specific for B. melitensis was found in the acetyl-CoA acetyltransferase gene. Primers were designed flanking this deletion and a short 12-mer MGB probe was placed over the area with 
Table 1 Reference strains tested to assess the sensitivity of Brucella melitensis specific real-time PCR assay

\begin{tabular}{|c|c|c|}
\hline Species & Biotype & Strain \\
\hline \multirow[t]{6}{*}{ B. melitensis } & 1 & $16 \mathrm{M}$ \\
\hline & 1 & ATCC 23456 \\
\hline & 1 & NCTC 10094 \\
\hline & 2 & NCTC10508 \\
\hline & 3 & NCTC 10509 \\
\hline & & 2065 \\
\hline \multirow[t]{10}{*}{ B. abortus } & 1 & ATCC 23448 \\
\hline & 1 & 544 \\
\hline & 1 & NCTC 00624 \\
\hline & 2 & NCTC10501 \\
\hline & 3 & NCTC10502 \\
\hline & 4 & NCTC10503 \\
\hline & 5 & NCTC10504 \\
\hline & 6 & NCTC10505 \\
\hline & 7 & NCTC10506 \\
\hline & 9 & NCTC10507 \\
\hline \multirow[t]{9}{*}{ B. suis } & 1 & ATCC 23444 \\
\hline & 1 & NCTC 10316 \\
\hline & 1 & NCTC 12042-01 \\
\hline & 2 & NCTC 10510 \\
\hline & 3 & NCTC 10511 \\
\hline & 4 & NC 10385-02 \\
\hline & 5 & NCTC 11996 \\
\hline & & 1720 \\
\hline & & 1030 \\
\hline \multirow[t]{5}{*}{ B. canis } & & ATCC 23365 \\
\hline & & SVA13 \\
\hline & & NCTC 10854 \\
\hline & & $3.4 .2008 / 122$ \\
\hline & & E20140122-106 \\
\hline \multirow[t]{2}{*}{ B. ovis } & & ATCC 25840 \\
\hline & & NCTC 10512 \\
\hline B. ceti & & NCTC 12891 \\
\hline B. inopinata & & CAPM 6436 \\
\hline B. microti & & CAPM 6434 \\
\hline B. neotomae & & ATCC 23459 \\
\hline B. pinnipedialis & & NCTC 12890 \\
\hline
\end{tabular}

the deletion. The forward nucleotide sequence 5'-GC TCGACACAAAGGGCCA-3' (Biomers, Germany) and the reverse nucleotide sequence $5^{\prime}$-CAAGCGTGGTCT GGCGA-3' (Biomers, Germany) were used with the FAMlabelled hydrolysis probe -CCGAGATACAAA-MGB (Applied Biosystems ${ }^{\odot}$ ).
The real-time PCR assays were carried out in $25 \mu \mathrm{L}$ reaction mixtures containing $5 \mu \mathrm{L}$ template DNA, in PerfeCta Multiplex qPCR SuperMix (Applied Biosystems $^{\oplus}$ ) diluted in UltraPure ${ }^{\mathrm{Tm}}$ DNase/RNase-Free Distilled Water (Invitrogen ${ }^{\mathrm{TM}}$ ), $0.9 \mu \mathrm{M}$ of each primer, and $0.2 \mu \mathrm{M}$ probe. Amplification and detection were performed using two different PCR machines, an ABI-7500/96-well plates real-time FAST PCR platform, and a StepOne Plus real-time PCR system (Applied Biosystems ${ }^{\oplus}$ ).

Thermocycling parameters were as follows: inactivation $95{ }^{\circ} \mathrm{C}$ for $3 \mathrm{~min}$, followed by 45 cycles $95^{\circ} \mathrm{C}$ for $3 \mathrm{~s}$, and annealing at $60{ }^{\circ} \mathrm{C}$ for $30 \mathrm{~s}$. The baseline and threshold were set using the auto-baseline and threshold feature in StepOneplus Software v2.2.2 (Applied Biosystems ${ }^{\circledR}$ ). Samples were considered positive if target amplification was detected within 40 cycles.

\section{Determination of the real-time PCR limit of detection}

The limit of detection (LOD) was defined by using the Brucella ATCC 23456 strain with $10^{6}, 10^{5}, 10^{4}, 10^{3}, 10^{2}$, $50,25,12.5,6.25,3.125,1.56,0.78,0.39$ genome equivalents per reaction. LOD samples were analysed in six replicates for each concentration and with five runs on 5 days (Fig. 1).

\section{Internal amplification control (IAC)}

As internal amplification control (IAC), Phocine Herpesvirus 1 (PhHV-1) aliquots with a known DNA concentration and a target quantification cycle $(\mathrm{Cq})$ of 32 was used [24].

\section{Results and discussion}

Real-time PCR is a rapid and reliable method for the analysis of Brucella in clinical samples. However, the high genomic similarity between different Brucella species makes the design of a species-specific real-time PCR assay difficult. An alternative attempt to use a probe (FAM-CCGCCGAGATACAAA) with Tm 68-70 ${ }^{\circ} \mathrm{C}$ (Primer Express v 3.0) resulted in a signal for all Brucella species, but also a signal for non-melitensis species. To increase the discriminatory effect, a shorter probe (FAM-CCGAGATACAAA-MGB) with Tm $57{ }^{\circ} \mathrm{C}$ was used. By using this shorter probe we could eliminate all the non-specific amplification derived from other Brucella species than B. melitensis.

The method was validated according to Broeders et al. 2014 [25] and according to the validation standards of the Swedish National Veterinary Institute (SVA), the Public Health Agency of Sweden (FOHM), the Swedish National Food Agency (NFA) and the Swedish Defense Research Agency (FOI). The validation comprised applicability, practicability, specificity, linearity, and sensitivity. 
Table 2 None Brucella strains used in the study for exclusivity test

\begin{tabular}{|c|c|}
\hline Species & Strain \\
\hline Actinobacillus pleuropneumoniae & CCUG 12837 \\
\hline Actinomyces pyogenes & CCUG 13230 \\
\hline Alcaligenes denitrificans & CCUG 407 \\
\hline Bacillus antracis & NCTC1328 \\
\hline Bacillus cereus & CCUG 7414 \\
\hline Bacillus subtilis & ATCC 6633 \\
\hline Bacteroides fragilis & ATCC 25285 \\
\hline Bordetella bronchiseptica & CCUG 219 \\
\hline Burkholderia mallei & NCTC120 \\
\hline Burkholderia pseudomallei & NCTC8707 \\
\hline Clostridium perfringens & CCUG 1795 \\
\hline Enterococcus fecalis & ATCC 29212 \\
\hline Erysipelotrix rhusiopatiae & CCUG 221 \\
\hline Escherichia coli & ATCC 35218 \\
\hline Escherichia coli (EHEC) & EDL333 \\
\hline Escherichia coli (VTEC) & 2954-06 \\
\hline Fusobacterium necrophorum & CCUG 9994 \\
\hline Haemophilus influenzae & ATCC 49247 \\
\hline Haemophilus somnus & CCUG 28029 \\
\hline Klebsiella oxytoca & CCUG 15717 \\
\hline Klebsiella pneumoniae & CCUG 225 \\
\hline Listeria monocytogenes & CCUG 15527 \\
\hline Nocardia asteroides & CCUG 10073 \\
\hline Ochrabactrum anthropi & ATCC 49188 \\
\hline Pasteurella multocida & CCUG 229 \\
\hline Pasteurella pneumotropica & CCUG 12398 \\
\hline Proteus mirabilis & CCUG 26767 \\
\hline Pseudomonas aeruginosa & CCUG 17619 \\
\hline Rhodococcus equi & CCUG 892 \\
\hline Salmonella Dublin & CCUG 35631 \\
\hline Salmonella Thyphimurium & CCUG 31969 \\
\hline Salmonella Zanzibar & CCUG 41921 \\
\hline Staphylococcus aureus & CCUG 4151 \\
\hline Staphylococcus intermedius & CCUG 49053 \\
\hline Streptobacillus moniliformis & CCUG 33440 \\
\hline Streptococcus agalactiae & CCUG 39325 \\
\hline Streptococcus dysgalactiae & CCUG 27436 \\
\hline Streptococcus equi & CCUG 27367 \\
\hline Streptococcus pyogenes & CCUG 12701 \\
\hline Streptococcus uberis & CCUG 27444 \\
\hline Streptococcus zooepidemicus & CCUG 23256 \\
\hline
\end{tabular}

Table 2 None Brucella strains used in the study for exclusivity test (Continued)

\begin{tabular}{ll}
\hline Taylorella equigenitalis & CCUG 16464 \\
Yersinia enterocolitica & CCUG 8239 \\
Yersinia pestis & $570-04$ \\
Yersinia pseudotuberculosis & CCUG 5855 \\
\hline
\end{tabular}

\section{Applicability}

No false positive or false negative result is acceptable in clinical BSL3 pathogen diagnostics. To guarantee a correct identification of BSL3- pathogens, we strongly recommend isolation of the bacteria on selective Brucella agar plates. This enables evaluation of the phenotypic properties of the strains, such as colony morphology, and enriches the molecular target of the PCR, as well as reduces the concentration of potential PCR inhibitors. Even after the enrichment an internal PCR process control is recommended as described above. All strains in our validation were cultured under the same conditions as bacterial strains were isolated in the clinical diagnostics workflow. The real-time PCR method was therefore recognized as applicable in combination with the isolation of bacteria from clinical specimens.

\section{Specificity}

The assay was tested with 120 human clinical B. melitensis isolates, 31 other non $B$. melitensis Brucella strains, 45 non $B$. melitensis strains, and 6 B. melitensis reference strains. There was no amplification from any other Brucella species other than $B$. melitensis. The specificity of this method was $100 \%$ because all 126 B. melitensis samples were tested positive while all 76 non- $B$. melitensis samples gave no amplification in the real-time PCR.

\section{Practicability}

The assay was used for the identification of Brucella samples from the first External Quality Assurance Exercises (EQAEs) on highly infectious agents (BSL-3) from the EU financed project "Efficient response to highly dangerous and emerging pathogens" (EMERGE). The results obtained with this assay conformed to the results of other laboratories.

\section{Sensitivity}

The limit of detection was 6.25 genome equivalents of $B$. melitensis (ATCC 23456) per reaction of template DNA $(1.25 \mathrm{GE} / \mu \mathrm{l})$. At a DNA concentration of 3.125 genome equivalents per reaction, $80 \%$ of the reactions were still positive (Fig. 1).

\section{Linearity}

The linear dynamic range of this PCR assay was determined by testing serially diluted DNA of $B$. melitensis 


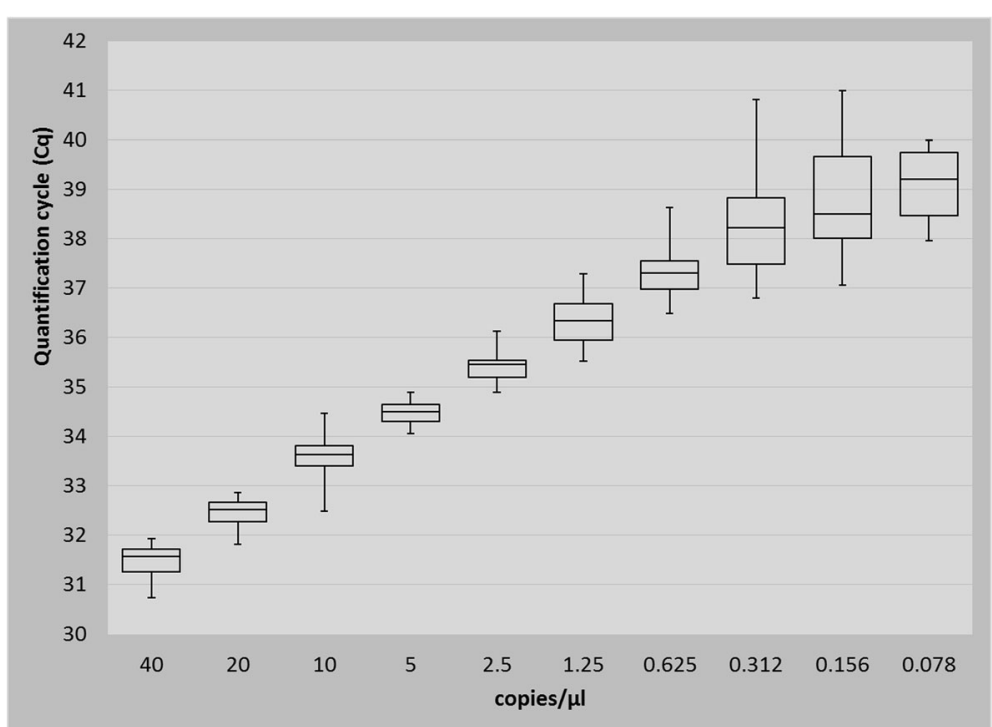

Fig. 1 Limit of detection was determined by assaying six replicates of ten and two fold serially diluted DNA of strain Brucella melitensis ATCC 23456 in five separate experiments. The number of positives per total number of replicates tested is shown in the figure

strain ATCC 23456. The regression coefficient calculated from the regression line in the standard curve was $\mathrm{R}^{2}=0.993$, y-intercept $=37.766$.

In conclusion, the novel real-time PCR assay is highly sensitive and reliable for the rapid detection of all biovars of B. melitensis. It is an important tool for diagnostic laboratories for clinical samples from both humans and animals.

\section{Conclusions}

This new real-time PCR method for the detection of all biovars of $B$. melitensis shows a high specificity (100\%) and a high sensitivity $(1.25 \mathrm{GE} / \mu \mathrm{l})$ and has been successfully implemented in laboratories of four governmental authorities across Sweden (National Food Agency, National Veterinary Institute, Swedish Defence Research Agency and The Public Health Agency of Sweden).

\section{Abbreviations}

ANI: Analysis and nonparametric inference; ATCC: American type culture collection; B: Brucella; BLAST: Basic local alignment search tool; BSL: Biosafety level; CCUG: Culture Collection University of Göteborg: Cq: Quantification cycle; DNA: Deoxyribonucleic acid; EMERGE: Efficient response to highly dangerous and emerging pathogens; EQAE: External quality assurance exercises; FAM: 6-carboxyfluorescein; FOHM: Public Health Agency of Sweden; IAC: Internal amplification control; LOD: Limit of detection; MALDI-TOF MS: Matrix assisted laser dessorption/lonization time of flight mass spectrometry; MGB: Minor groove binder; NCBI: National Center for Biotechnology Information; NCTC: National collection of type cultures; NFA: National food agency; PCR: Polymerase chain reaction; PhHV-1: Phocine herpesvirus 1; SVA: National Veterinary Institute; Tm: Melting temperature

\section{Acknowledgements}

The authors gratefully thank Martina Lindberg, Stina Bäckman and Talar Boskani for technical assistance, Nina Lagerqvist, Annelie Lundin Zumpe, Anna-Lena Johansson and Moa Lavander for fruitful discussion, Öjar Melfors, Romanico Arrighi and Leigh Davidsson for critical reading of the manuscript.
We thank Finnish Food Safety Authority Evira for sending us their two Brucella canis isolates 3.4.2008/122 and E2014122-106.

\section{Funding}

This project is part of ongoing work to develop and harmonise methods to increase the level of biopreparedness in Sweden and is performed within the Forum for Biopreparedness Diagnostics (FBD), involving four governmental institutes: the National Veterinary Institute (SVA), the Public Health Agency of Sweden (FOHM), the National Food Agency (NFA), and the Swedish Defence Research Agency (FOI) financed by by the Swedish Civil Contingencies Agency. The new real-time PCR method was also tested at the Swedish Laboratory for Food Safety and Biopreparedness (RUB), as a collaborative effort of the SVA and the NFA.

\section{Availability of data and materials}

All available genomes in the public database of Brucella $(N=96)$, including all complete genomes of $B$. melitensis $(N=17)$, were used in the design of primers and probes in August 2016.

\section{Authors' contributions}

EA carried out the sequence analysis, RK participated in the design of the study and drafted the manuscript. SF carried out the exclusivity test. TW conceived the study, participated in its design, drafted the manuscript, and performed most of the laboratory work. All authors read and approved the final manuscript.

\section{Competing interests}

The authors declare that they have no competing interests.

\section{Consent for publication}

Not applicable.

\section{Ethics approval and consent to participate}

Ethical Review of Research Involving Humans is not applicable for diagnostic development and quality assessment. In this study we used an historical collection of Brucella from the Public Health Agency of Sweden. No data from human patients were used, therefore informed consent was not required.

\section{Publisher's Note}

Springer Nature remains neutral with regard to jurisdictional claims in published maps and institutional affiliations. 


\section{Author details}

Department of Medical Sciences, Clinical Microbiology, Uppsala University, Uppsala, Sweden. ${ }^{2}$ National Veterinary Institute, Uppsala, Sweden. ${ }^{3}$ Swedish Forum for Biopreparedness Diagnostics, Stockholm, Umeå and Uppsala, Sweden. ${ }^{4}$ Department of Microbiology, The Public Health Agency of Sweden, Stockholm, Sweden.

Received: 16 November 2016 Accepted: 16 March 2017

Published online: 24 March 2017

\section{References}

1. Pappas G, Akritidis N, Tsianos EV. Brucellosis - Reply. New Engl J Med. 2005; 353(10):1072.

2. Seleem MN, Boyle SM, Sriranganathan N. Brucellosis: a re-emerging zoonosis. Vet Microbiol. 2010;140(3-4):392-8

3. Pappas G, Akritidis N, Bosilkovski M, Tsianos E. Brucellosis. N Engl J Med. 2005;352(22):2325-36.

4. Young EJ. Human brucellosis. Rev Infect Dis. 1983;5(5):821-42.

5. Whatmore AM. Current understanding of the genetic diversity of Brucella, an expanding genus of zoonotic pathogens. Infect Genet Evol. 2009;9(6): 1168-84.

6. Whatmore AM, Davison N, Cloeckaert A, Al Dahouk S, Zygmunt MS, Brew SD, Perrett LL, Koylass MS, Vergnaud G, Quance C, et al. Brucella papionis sp. nov., isolated from baboons (Papio spp.). Int J Syst Evol Microbiol. 2014; 64(Pt 12):4120-8.

7. European Commission. Commission Decision of 23 June 2003 establishing the official tuberculosis, brucellosis, and enzootic-bovine-leukosis-free status of certain Member States and regions of Member States as regards bovine herds (Text with EEA relevance) (notified under document number C(2003). EC Official J. 2003;(L156):0074-0078.

8. Rolfhamre P, Jansson A, Arneborn M, Ekdahl K. SmiNet-2: Description of an internet-based surveillance system for communicable diseases in Sweden. Euro Surveill. 2006;11(5):103-7.

9. Al Dahouk S, Tomaso H, Nockler K, Neubauer H, Frangoulidis D. Laboratorybased diagnosis of brucellosis-a review of the literature. Part II: serological tests for brucellosis. Clin Lab. 2003;49(11-12):577-89.

10. Garofolo G, Fasanella A, Di Giannatale E, Platone I, Sacchini L, Persiani T, Boskani T, Rizzardi K, Wahab T. Cases of human brucellosis in Sweden linked to Middle East and Africa. BMC Res Notes. 2016;9(1):277.

11. DelVecchio VG, Kapatral V, Redkar RJ, Patra G, Mujer C, Los T, Ivanova N, Anderson I, Bhattacharyya A, Lykidis A, et al. The genome sequence of the facultative intracellular pathogen Brucella melitensis. Proc Natl Acad Sci U S A. 2002;99(1):443-8.

12. Halling SM, Peterson-Burch BD, Bricker BJ, Zuerner RL, Qing Z, Li LL, Kapur V, Alt DP, Olsen SC. Completion of the genome sequence of Brucella abortus and comparison to the highly similar genomes of Brucella melitensis and Brucella suis. J Bacteriol. 2005;187(8):2715-26.

13. Paulsen IT, Seshadri R, Nelson KE, Eisen JA, Heidelberg JF, Read TD, Dodson RJ, Umayam L, Brinkac LM, Beanan MJ, et al. The Brucella suis genome reveals fundamental similarities between animal and plant pathogens and symbionts. Proc Natl Acad Sci U S A. 2002;99(20):13148-53.

14. Wahab T, Ferrari S, Lindberg M, Backman S, Kaden R. Draft Genome Sequences of Brucella suis Biovar 4 Strain NCTC 10385, Brucella ceti Strain NCTC 12891T, Brucella inopinata Strain CAMP 6436T, and Brucella neotomae Strain ATCC 23459T. Genome Announc. 2014;2(5).

15. Garcia-Yoldi D, Marin CM, de Miguel MJ, Munoz PM, Vizmanos JL, LopezGoni I. Multiplex PCR assay for the identification and differentiation of all Brucella species and the vaccine strains Brucella abortus S19 and RB51 and Brucella melitensis Rev1. Clin Chem. 2006;52(4):779-81.

16. Yu WL, Nielsen K. Review of detection of Brucella spp. by polymerase chain reaction. Croat Med J. 2010;51(4):306-13.

17. Bricker BJ, Halling SM. Differentiation of Brucella abortus bv. 1, 2, and 4, Brucella melitensis, Brucella ovis, and Brucella suis bv. 1 by PCR. J Clin Microbiol. 1994;32(11):2660-6.

18. Ocampo-Sosa AA, Aguero-Balbin J, Garcia-Lobo JM. Development of a new PCR assay to identify Brucella abortus biovars 5, 6 and 9 and the new subgroup 3b of biovar 3. Vet Microbiol. 2005;110(1-2):41-51.

19. Huber B, Scholz HC, Lucero N, Busse HJ. Development of a PCR assay for typing and subtyping of Brucella species. Int J Med Microbiol. 2009; 299(8):563-73.
20. Kim J-Y, Kang S-I, Lee JJ, Lee K, Sung S-R, Erdenebaataar J, Vanaabaatar B, Jung SC, Park YH, Yoo H-S, et al. Differential diagnosis of Brucella abortus by real-time PCR based on a single-nucleotide polymorphisms. J Vet Med Sci. 2016:78(4):557-62

21. Andriopoulos P, Tsironi M. Molecular Diagnosis of Brucellosis: A Brief Report. Adv Mol Diagn. 2016;1(2):108-10.

22. Drevinek M, Dresler J, Klimentova J, Pisa L, Hubalek M. Evaluation of sample preparation methods for MALDI-TOF MS identification of highly dangerous bacteria. Lett Appl Microbiol. 2012;55(1):40-6.

23. Lista F, Reubsaet FA, De Santis R, Parchen RR, de Jong AL, Kieboom J, van der Laaken AL, Voskamp-Visser IA, Fillo S, Jansen HJ, et al. Reliable identification at the species level of Brucella isolates with MALDI-TOF-MS. BMC Microbiol. 2011;11:267.

24. van Doornum GJJ, Guldemeester J, Osterhaus ADME, Niesters HGM. Diagnosing Herpesvirus Infections by Real-Time Amplification and Rapid Culture. J Clin Microbiol. 2003;41(2):576-80.

25. Broeders S, Huber I, Grohmann L, Berben G, Taverniers I, Mazzara M, Roosens $\mathrm{N}$, Morisset D. Guidelines for validation of qualitative real-time PCR methods. Trends Food Sci Technol. 2014;37(2):115-26.

\section{Submit your next manuscript to BioMed Central and we will help you at every step:}

- We accept pre-submission inquiries

- Our selector tool helps you to find the most relevant journal

- We provide round the clock customer support

- Convenient online submission

- Thorough peer review

- Inclusion in PubMed and all major indexing services

- Maximum visibility for your research

Submit your manuscript at www.biomedcentral.com/submit 